\title{
As organizações e a ISO 26000: revisão dos conceitos, dos motivadores e das barreiras de implementação
}

\section{Organizations and ISO 26000: review of concepts, motivators, and barriers to implementation}

\author{
Rafael Mattos de Deus ${ }^{1}$ \\ Bruno Michel Roman Pais Seles ${ }^{1}$ \\ Karina Rabelo Ogasawara Vieira ${ }^{1}$
}

\begin{abstract}
Resumo: A ISO 26000, publicada em 2010, trata sobre o tema de Responsabilidade Social das Organizações. Esse estudo apresenta uma revisão sistemática nas bases de dados ISI Web of Science e Scopus sobre a questão: "quais são as barreiras e motivadores da adoção da ISO 26000 para as organizações?". Os artigos foram selecionados por filtros baseados em dois critérios de inclusão. Os dados foram sumarizados em uma tabela abrangendo os conceitos de ISO 26000, os motivadores e as barreiras. Os motivadores encontrados foram: globalização - competição em mercados internacionais; congruência com sistemas de gestão; reputação (imagem) da empresa; relação com os funcionários e melhora do ambiente organizacional; melhora na relação com stakeholders externos; vantagem competitiva/estratégias; guia para a Responsabilidade Social Corporativa (RSC); e diminuição dos riscos do negócio. As barreiras encontradas foram: falta de alinhamento da RSC com a estratégia organizacional; comercial (nacional e internacional); falta de compreensão da ISO 26000; falta de comunicação; falta de ferramentas; falta de sensibilidade ao tema; foco no curto prazo; gestão do conhecimento; receio em não cumprir a norma; recursos financeiros. Por fim, uma agenda para estudos futuros foi elaborada.
\end{abstract}

Palavras-chave: Organizações. ISO 26000. Responsabilidade Social. Motivadores. Barreiras. Sustentabilidade.

\begin{abstract}
ISO 26000, published in 2010, focuses on corporate social responsibility. This study presents a systematic review conducted in ISI Web of Knowledge (Web of Science) and Elsevier's Scopus databases to answer the following question: "What are the barriers and motivators affecting the adoption of ISO 26000 by organizations?" The articles were selected using filters that applied two inclusion criteria. The data were summarized in a table covering the concepts of ISO 26000, the motivators, and the barriers. The motivators were globalization or competition in international markets, congruence with management systems, reputation or image, relationship with employees and improvement of the organizational environment, improvement in the relationship with external stakeholders, competitive advantage and strategy, guide to corporate social responsibility (CSR), and reduction of business risks. The barriers were lack of alignment between CSR and organizational strategy; business (national and international); unfamiliarity with ISO 26000; lack of communication, tools and sensitivity to the subject; short-term focus; knowledge management; fear of not fulfilling the standard; and financial resources. Finally, an agenda for future studies was prepared.
\end{abstract}

Keywords: Organizations. ISO 26000. Social Responsibility. Motivators. Barriers. Sustainability.

\section{Introdução}

Os padrões e normas internacionais facilitam o comércio entre os países, ajudam a garantir uma compatibilidade e viabilidade técnica dos produtos comercializados, além de transmitir aos consumidores informações necessárias sobre o produto, tais como qualidade e desempenho. Assim a International Organization for Standardization (ISO), uma organização não governamental criada em 1947, tem o propósito de criar tais padrões (WARD, 2011). A princípio, na década de 1980, esta organização desenvolveu a ISO 9000, um sistema genérico de gestão da qualidade aceito pelas empresas em todo o mundo; logo depois, em 1996 foi criada a ISO 14000 para a gestão ambiental (CASTKA; BALZAROVA, 2008d).

A ISO trabalha em várias normativas ligadas às políticas públicas, emissões de carbono, saúde e segurança, e nanotecnologia; então, para complementar este escopo, em 2010 a ISO aprovou uma norma ambiciosa, que levou cinco anos de desenvolvimento, sobre a Responsabilidade Social das Organizações, denominada de ISO 26000 (WARD, 2011).

\footnotetext{
${ }^{1}$ Programa de Engenharia de Produção, Faculdade de Engenharia de Bauru, Universidade Estadual Paulista - UNESP, CEP 17033-360, Bauru, SP, Brasil, e-mail: rafaelmd@usp.br; bruno_seles@yahoo.com.br; rabelo.karina@ gmail.com
} 
Vale ressaltar que o tema Responsabilidade Social Corporativa (RSC) e seus impactos nas organizações é um dos assuntos mais em pauta na literatura acadêmica do século 21. Vaaland, Heide e Grønhaug (2008, p. 931) definem RSC como

[...] gestão do interesse do stakeholder para atos de responsabilidade e irresponsabilidade em relação ao fenômeno ambiental, ético e social de forma a criar um benefício corporativo.

Este tema entrou na pauta do debate de sustentabilidade nas organizações, devido às pressões da globalização e das organizações não governamentais (ONGs) (SCHWARTZ; TILLING, 2009). Até mesmo o conceito de desenvolvimento sustentável, criado na Conferência das Nações Unidas sobre Meio Ambiente e Desenvolvimento, em 1992, integra os aspectos ambientais nas atividades políticas, econômicas e sociais (ELKINGTON, 1994). Vale enfatizar que uma empresa sustentável

[...] é aquela que contribui para o desenvolvimento sustentável ao gerar, simultaneamente, benefícios econômicos, sociais e ambientais - conhecidos como os três pilares do desenvolvimento sustentável (HART; MILSTEIN, 2004, p. 66).

As ONGs e a mídia mundial têm destacado as más condições de trabalho em países de baixa renda, tais como baixa remuneração, longas jornadas de trabalho, baixos impostos, entre outros. Ou seja, a exploração de pessoas apenas para trazer mais lucros para as corporações e produzir bens baratos (SCHWARTZ; TILLING, 2009). Neste cenário é que se torna importante o desenvolvimento da padronização da responsabilidade social e, consequentemente, a implementação da ISO 26000.

Por outro lado, Banerjee (2012, p. 74) critica a responsabilidade social nas corporações, levantando a questão de que as empresas não podem assumir o papel dos governos para garantir o bem-estar social, pois suas necessidades econômicas são as funções básicas, portanto não há como haver esta substituição. Ele acrescenta a seguinte questão:

[...] o que aconteceria com a comunidade local que é completamente dependente do bem-estar econômico, social e ambiental de uma empresa multinacional?.

Pode-se observar uma crítica implícita no trabalho de Drucker (1992), pois diz que, diferentemente de 'comunidades', 'sociedade' ou 'família', as organizações são planejadas e especializadas, portanto são definidas por sua tarefa. $\mathrm{O}$ autor defende que a organização só é eficaz se concentrar-se em uma tarefa, pois a diversificação destrói a capacidade de desempenho. Portanto esta definição atinge a Responsabilidade Social e levanta os questionamentos: qual sua real contribuição para as corporações? As organizações têm responsabilidades para com a sociedade?

Ao contrário de tais pensamentos, a Escola de Gestão Ambiental, com início na década de 1990, tem direcionado os esforços para o desenvolvimento sustentável, com estratégias de interesse social, promoção ecológica e do bem-estar das pessoas (HOLT, 1999). Portanto é importante entender o papel da organização corporativa e sua responsabilidade para com a sociedade. Assim, neste importante contexto, se instala o objetivo deste trabalho em realizar uma revisão sistemática da literatura para reunir os conceitos da ISO 26000, assim como identificar os motivadores e barreiras para sua adoção, e criar uma agenda para estudos futuros relacionados ao tema.

\section{Fundamentação teórica}

\subsection{A ISO 26000 e seus aspectos como norma em Responsabilidade Social}

A Norma de Orientação em Responsabilidade Social ISO 26000 foi elaborada pelo ISO/TMB Working Group on Social Responsibility (ISO/TMB WG SR). Seu processo de elaboração envolveu especialistas de 90 países e 40 organizações internacionais, com ampla atuação regional, envolvidos em diferentes aspectos da responsabilidade social (ASSOCIAÇÃO..., 2010), ou seja, foi constituído um Grupo de Trabalho sobre responsabilidade social composto por seis subgrupos: Indústria; Serviços, Suporte, Pesquisa e Outros; Governos; ONGs; Consumidores e Trabalhistas. Este tipo de abordagem multi-stakeholder é essencial para o desenvolvimento de normas sociais e ambientais (BALZAROVA; CASTKA, 2012).

A ISO 26000 foi publicada no dia $1^{\circ}$ de novembro de 2010 em Genebra, Suíça. A versão em português da norma, a ABNT NBR ISO 26000 (ASSOCIAÇÃO..., 2010), foi lançada no Brasil no dia 8 de dezembro de 2010 e está disponível na íntegra no site do Instituto Nacional de Metrologia, Qualidade e Tecnologia (INMETRO).

Embora seja uma norma, a ISO 26000 serve como orientação não certificável, que "pretende auxiliar as organizações a contribuírem para o desenvolvimento sustentável", além de aconselhar as organizações a observarem as diversidades sociais, ambientais, econômicas, jurídicas, culturais, políticas e organizacionais dos países em que atuam, mantendo a consistência com as normas internacionais de comportamento (ASSOCIAÇÃO..., 2010).

Nesse sentido, as organizações devem contribuir para o desenvolvimento sustentável, definido como

[...] desenvolvimento que satisfaz as necessidades do presente sem comprometer a capacidade das gerações futuras de satisfazerem as suas próprias necessidades [...] (WORLD..., 1987, p. 21), 
visando empregar os sete princípios para a responsabilidade social (ASSOCIAÇÃO..., 2010):

1. Accountability: a organização deve se responsabilizar por seus impactos na sociedade, economia e meio ambiente;

2. Transparência: agir com transparência nas decisões e atividades organizacionais que impactam a sociedade e o meio ambiente;

3. Comportamento ético: comportar-se com honestidade, equidade e integridade. Adotar e aplicar padrões éticos de comportamento de acordo com as atividades organizacionais desenvolvidas;

4. Respeito pelos interesses dos stakeholders: identificar todos os stakeholders e respeitar seus direitos legítimos, e considerar outros interesses de todos os indivíduos e não apenas dos proprietários e acionistas;

5. Respeito pelo estado de direito: cumprir com a legislação de todas as jurisdições em que operar, manter-se atualizado para estar sempre em conformidade com a lei;
6. Respeito pelas normas internacionais de comportamento: em situações em que a legislação não apresentar normas de proteção socioambiental adequada, deve-se, no mínimo, respeitar as normas internacionais de comportamento. Evitar ser cúmplice de atividades que não respeitam as normas internacionais de comportamento;

7. Respeito pelos direitos humanos: respeitar e, se possível, promover os direitos previstos na Declaração Internacional dos Direitos Humanos. Em situações em que os direitos humanos não forem protegidos, nunca tirar vantagens e respeitar as normas internacionais de comportamento.

A ISO 26000 estimula as organizações a ultrapassarem a conformidade legal, reconhecendo que conformidade com a lei é uma obrigação fundamental para qualquer organização e parte essencial de sua responsabilidade social (ASSOCIAÇÃO..., 2010).

A norma salienta que a governança organizacional é a chave para que a organização se responsabilize pelas consequências de suas decisões e pelos impactos de suas atividades. A Figura 1 apresenta a relação

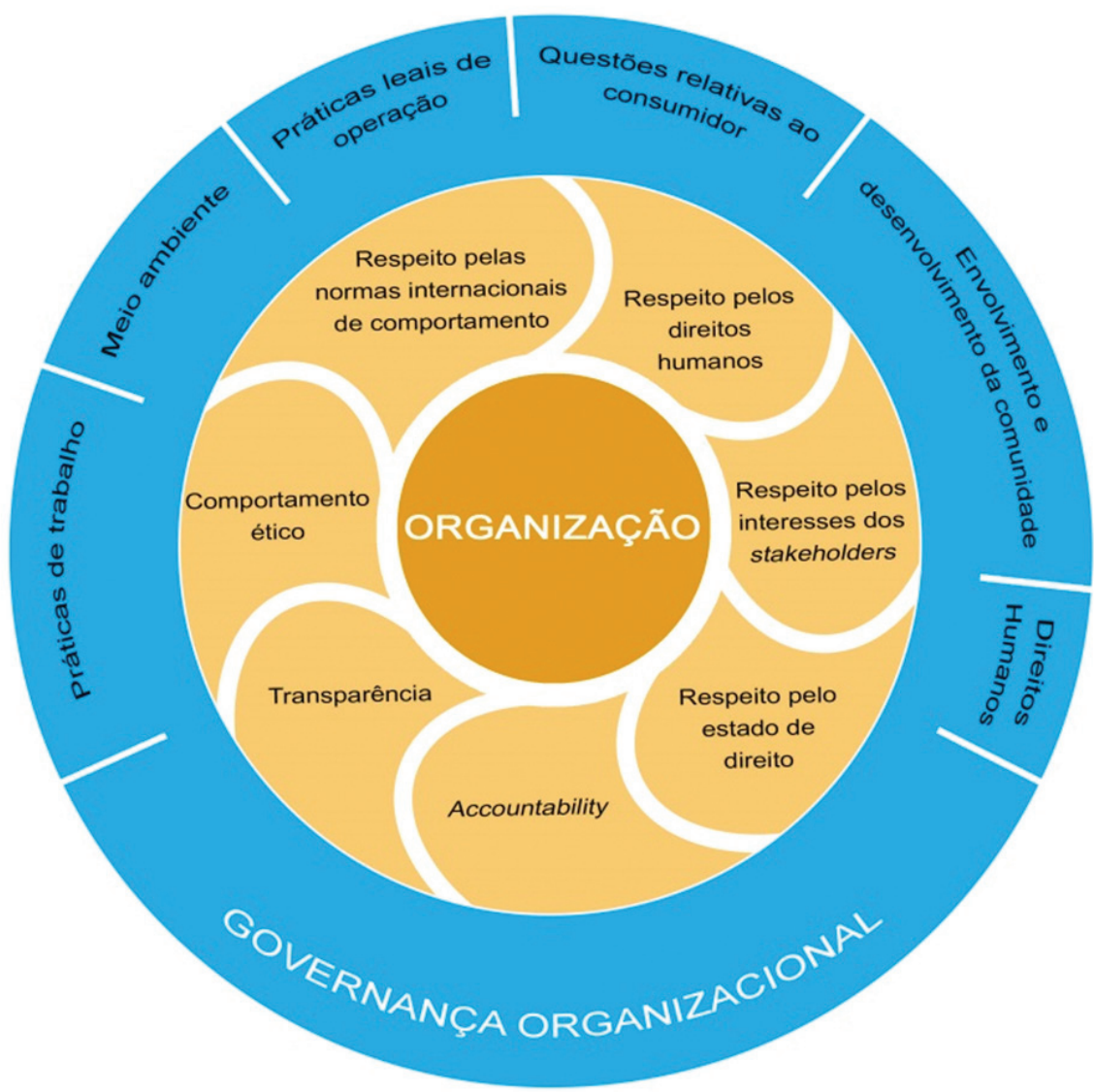

Figura 1. Relação da Organização e os Princípios da Responsabilidade Social (temas centrais da ISO 26000) relacionando com a Governança Organizacional. Fonte: Baseado na ABNT NBR ISO 26000:2010 (ASSOCIAÇÃO..., 2010). 
dos princípios, a serem incutidos na organização, da responsabilidade social (ISO 26000) com a Governança Organizacional (Direitos Humanos, Práticas de Trabalho, Meio Ambiente, Práticas Leais de Operação, Questões Relativas ao Consumidor, e Envolvimento e Desenvolvimento da Comunidade).

Os temas centrais da ISO 26000, resumidos no Quadro 1, discutem sobre os fatores sociais, ambientais e econômicos que as consequências organizacionais atingem.

Algumas características para a adoção da ISO 26000 (ASSOCIAÇÃO..., 2010) são:

- Incutir a Responsabilidade Social na governança, sistemas, procedimentos e política da empresa, bem como nas diretrizes organizacionais (missão, visão, valores). Desenvolver as competências dos recursos humanos para a responsabilidade social por meio de treinamentos;

- Comunicar, conscientizar e motivar a prática da responsabilidade social para criar uma cultura organizacional socioambientalmente responsável. Todos os stakeholders devem ser envolvidos na discussão sobre a colaboração com a responsabilidade social;

- Fortalecer a credibilidade e a imagem da empresa por meio de relatórios e declarações sobre responsabilidade social. Os eventuais conflitos ou desavenças entre a organização e seus stakeholders devem ser resolvidos prontamente;

- As atividades de responsabilidade social devem ser monitoradas para assegurar sua efetividade. Bem como, deve-se analisar o progresso e o desempenho da responsabilidade social e buscar aprimorar seu desempenho;

- Por fim, deve-se contribuir com o governo, ONGs e público em geral ao fornecer informações detalhadas sobre as ações da empresa.

Como a ISO 26000 traz a universalidade da Responsabilidade Social, na qual o Estado e as organizações são responsáveis pelo desenvolvimento social, vale destacar e enfatizar a evolução do conceito de Responsabilidade Social (RS) e suas funções organizacionais, resumidas no Quadro 2.

Nesse contexto, revela-se a importância da prática da Responsabilidade Social para que as organizações contribuam para a redução da pobreza e promoção de meios de vida sustentáveis (SIEGELE; WARD, 2007). Estes aspectos estão em consonância com os oito objetivos de desenvolvimento do milênio estabelecidos pela ONU: 1. Erradicar a extrema pobreza e a fome; 2. Atingir o ensino básico universal; 3. Promover a igualdade entre os sexos e a autonomia das mulheres; 4. Reduzir a mortalidade infantil; 5. Melhorar a saúde materna; 6. Combater o HIV/AIDS, a malária e outras doenças; 7. Garantir a sustentabilidade ambiental; 8. Estabelecer uma parceria mundial para o desenvolvimento.

\subsection{Fatores de motivação para adoção da ISO 26000}

A motivação é essencialmente sobre como identificar as principais necessidades que influenciam o comportamento, no caso do comportamento do indivíduo, e tomar medidas para satisfazê-las (MASLOW, 1954). A motivação também se preocupa com os fatores que influenciam o comportamento em termos de direção, esforço e persistência. A direção é o que a pessoa está tentando fazer. O esforço é o quão difícil o que se está tentando fazer. Já a persistência é o tempo que uma pessoa continuará tentando fazer aquilo que se pretende (ARNOLD; ROBERTSON; COOPER, 1991).

Para Garcia (2006), os motivadores para adoção do desenvolvimento sustentável pelas organizações são, basicamente, de caráter: social, ambiental, econômico e estratégico. Por exemplo, o motivador social pode ser representado pelo desenvolvimento da comunidade e redução da pobreza. O motivador ambiental, pela escassez de recursos naturais. $\mathrm{O}$ motivador econômico, pelo desenvolvimento econômico. Já o motivador estratégico, pela viabilidade do negócio e imagem da organização (GARCIA, 2006). No caso do caráter estratégico, as organizações que possuem um planejamento estratégico formal tendem ao tratamento de questões comerciais e não comerciais, como a Responsabilidade Social Corporativa (RSC). Essas organizações acompanham o ambiente em que estão inseridas, direcionando esforços para as mais variadas questões, inclusive RSC. O planejamento estratégico permite uma visão profunda sobre a demanda por responsabilidade social, que possibilita a implementação de políticas e práticas de RSC (KALYAR; RA; KALYAR, 2013).

No caso da adoção de certificações, como a ISO 26000, um importante motivador é a influência dos stakeholders. Para Kalyar, Ra e Kalyar (2013), os stakeholders compreendem um ponto crítico no desenvolvimento estratégico, pois compreender seus anseios é uma questão de sobrevivência para a organização. Diferentes stakeholders influenciam a adoção de diferentes certificações, como apresentado por Qi et al. (2013) em um estudo realizado na China. Para a ISO 9001, por exemplo, clientes estrangeiros e a comunidade vizinha são motivadores significantes. Investidores estrangeiros e a comunidade vizinha demonstram um impacto significativo na adoção da ISO 14001. Já para a OHSAS 18001, certificação com objetivos sociais, a publicidade por si só é um motivador para a sua adoção.

Kalyar, Ra e Kalyar (2013) apresentam ainda que a cultura organizacional também é um motivador para a inclinação, ou não, à adoção de políticas e práticas de RSC. 
Quadro 1. Responsabilidade das organizações de acordo com os temas centrais da ISO 26000.

\begin{tabular}{|c|c|}
\hline Temas Centrais & Responsabilidade da Organização \\
\hline $\begin{array}{c}\text { Governança } \\
\text { Organizacional }\end{array}$ & $\begin{array}{l}\text { Ter um sistema de governança que pratique e supervisione os princípios da responsabilidade } \\
\text { social. Estabelecendo uma cultura e um ambiente com atividades práticas que reflitam seu } \\
\text { compromisso. } \\
\text { As estratégias, objetivos e metas devem ser estabelecidos sob uma visão do compromisso com } \\
\text { a responsabilidade social, equilibrando as necessidades imediatas e futuras da organização } \\
\text { e de seus stakeholders. Cabe à organização envolver todos os níveis de trabalhadores } \\
\text { equilibrando o nível de autoridade, responsabilidade e capacidade das pessoas que tomam } \\
\text { decisões na empresa. Analisar e avaliar processos de governança da organização ajustando-os } \\
\text { de acordo com os resultados e comunicando as mudanças em toda a organização. }\end{array}$ \\
\hline $\begin{array}{l}\text { Direitos } \\
\text { Humanos }\end{array}$ & $\begin{array}{l}\text { Respeitar a Declaração Internacional dos Direitos Humanos e os direitos fundamentais do } \\
\text { trabalho identificados pela Organização Internacional do Trabalho (OIT). Em uma perspectiva } \\
\text { pró-ativa somar esforços com o governo para viabilizar o cumprimento dos direitos } \\
\text { econômicos, sociais e culturais; facilitar o acesso da comunidade à educação; adaptar bens e } \\
\text { serviços ao poder de compra dos pobres etc. }\end{array}$ \\
\hline $\begin{array}{l}\text { Práticas de } \\
\text { Trabalho }\end{array}$ & $\begin{array}{l}\text { O cumprimento das normas, princípios e direitos básicos do trabalho estabelecido pela } \\
\text { Organização Internacional do Trabalho (OIT), contribui para que as empresas não realizem } \\
\text { abusos e concorrência desleal. As empresas também devem seguir as leis estabelecidas pelos } \\
\text { seus países, independente das exigências ou apoio oferecido pelos governos. Os trabalhos } \\
\text { na empresa devem ser realizados por homens e mulheres legalmente reconhecidos como } \\
\text { empregados ou como autônomos. Os funcionários devem ser tratados com igualdade sem } \\
\text { prática de discriminação, recebendo informaçóes necessárias para desenvolver as atividades } \\
\text { esperadas. Quando a empresa estabelece um código de práticas de trabalho que devem ser } \\
\text { observados pelos fornecedores e terceirizados deve-se observar sua consistência em relação à } \\
\text { Declaração Universal dos Direitos Humanos e as normas internacionais do trabalho. }\end{array}$ \\
\hline Meio Ambiente & $\begin{array}{l}\text { Gerenciar o meio ambiente. Responsabilizar-se pelos impactos ambientais causados pelas } \\
\text { atividades organizacionais. Obedecer a legislação e implementar uma Gestão Ambiental } \\
\text { eficaz. Empregar práticas operacionais, princípios, abordagens e estratégias cabíveis para } \\
\text { prevenir a poluição, otimizar a utilização de recursos naturais, minimizar resíduos, emissões, } \\
\text { efluentes. Contribuir para a mitigação das mudanças climáticas, preservação do meio } \\
\text { ambiente, da biodiversidade e restauração dos hábitats naturais. }\end{array}$ \\
\hline $\begin{array}{c}\text { Práticas Leais de } \\
\text { Operação }\end{array}$ & $\begin{array}{l}\text { Os resultados positivos podem ser obtidos ao exercer liderança e promover a adoção de } \\
\text { responsabilidade social. A empresa deve implementar políticas e práticas de combate à } \\
\text { corrupção, treinando e conscientizando seus empregados, representantes, terceirizados e } \\
\text { fornecedores a erradicar o suborno e denunciar violações das políticas da organização. } \\
\text { Prepará-los para lidar com atividades políticas e conflitos de interesse. As políticas } \\
\text { organizacionais da empresa devem ser transparentes. As práticas devem influenciar a cadeia } \\
\text { a atingir objetivos socialmente responsáveis. Ações como doações políticas que possam ser } \\
\text { percebidas como influências indevidas devem ser evitadas. Assim como, buscar vantagens } \\
\text { competitivas injustas levando vantagem de condições sociais como a pobreza. Quando as } \\
\text { empresas reconhecem o direito de propriedade elas estimulam a criação e inovação. }\end{array}$ \\
\hline $\begin{array}{l}\text { Questões } \\
\text { Relativas ao } \\
\text { Consumidor }\end{array}$ & $\begin{array}{l}\text { Seguir as Diretrizes das Nações Unidas para a Proteção do Consumidor e o Pacto } \\
\text { Internacional dos Direitos Econômicos, Sociais e Culturais. Sempre disponibilizar as } \\
\text { informações precisas, empregar práticas de marketing leais e processos contratuais justos, } \\
\text { transparentes e úteis, promover o consumo sustentável, investir no design de produtos e } \\
\text { serviços que ofereçam acesso a todos, quando apropriado, cuidar dos mais vulneráveis e } \\
\text { desprivilegiados. Buscar a minimização de riscos decorrentes do uso de produtos e serviços, } \\
\text { empregando procedimentos de design, fabricação, distribuição, prestação de informaçôes, } \\
\text { serviços de suporte, retirada de produto do mercado e recall. Proteger a segurança das } \\
\text { informações e a privacidade dos consumidores. Prestar serviço de atendimento ao consumidor. }\end{array}$ \\
\hline
\end{tabular}

Fonte: Baseado na ABNT NBR ISO 26000:2010 (ASSOCIAÇÃO..., 2010). 
Quadro 1. Continuação...

\begin{tabular}{|c|l|}
\hline Temas Centrais & \multicolumn{1}{c|}{ Responsabilidade da Organização } \\
\hline & $\begin{array}{l}\text { As empresas precisam considerar-se parte da comunidade, agindo na prevenção e solução } \\
\text { de alguns problemas. Devem reconhecer características culturais, religiosas, tradições, } \\
\text { histórias e as necessidades da comunidade ao interagir com ela. A expansão e diversificação } \\
\text { das atividades econômicas e do desenvolvimento tecnológico trazem contribuições para } \\
\text { a comunidade, como geração de empregos, cursos de qualificação, instruções e cuidados } \\
\text { com a saúde. A criação de um ambiente que traga benefícios duradouros promovendo } \\
\text { renda e gerando riqueza por meio do incentivo ao empreendedorismo e cooperativismo. } \\
\text { As organizações devem formular políticas, implementação e avaliação de programas de } \\
\text { desenvolvimento. Atuar junto à autoridade competente ou organizações humanitárias em } \\
\text { Desenvolvimento } \\
\text { da Comunidade } \\
\text { situações de crise, desastres inesperados, e catástrofes. Combater a pobreza, atingir a meta } \\
\text { de emprego produtivo, adequadamente remunerado e livremente escolhido, e promover a } \\
\text { integração social como objetivo primordial de desenvolvimento. A Declaração do Milênio } \\
\text { da ONU estabelece objetivos que, se atingidos, ajudariam a resolver os principais desafios } \\
\text { mundiais de desenvolvimento. A Declaração do Milênio das Nações Unidas salienta que, } \\
\text { embora convenha que o desenvolvimento seja orientado e conduzido principalmente pelas } \\
\text { políticas públicas, o processo de desenvolvimento depende das contribuições de todas as } \\
\text { organizações. O envolvimento da comunidade ajuda a contribuir, em nível local, para o } \\
\text { alcance desses objetivos. A Declaração do Rio sobre Meio Ambiente e Desenvolvimento } \\
\text { introduziu a Agenda 21, a qual é um processo para desenvolver um plano de ação abrangente } \\
\text { que pode ser implementado localmente por organizações em cada área em que atividades } \\
\text { humanas impactem a sociedade e o meio ambiente. }\end{array}$ \\
\hline
\end{tabular}

Fonte: Baseado na ABNT NBR ISO 26000:2010 (ASSOCIAÇÃO..., 2010).

Quadro 2. Resumo da evolução do conceito de Responsabilidade Social.

\begin{tabular}{|c|c|}
\hline Data - Autores & Abordagem \\
\hline $\begin{array}{l}\text { 1953: } \\
\text { Howard Bowen; }\end{array}$ & $\begin{array}{l}\text { As empresas têm um poder de decisão que pode influenciar suas ações e têm } \\
\text { impacto na sociedade como um todo. }\end{array}$ \\
\hline $\begin{array}{l}\text { Década de 1960: } \\
\text { Davis; } \\
\text { Frederick; } \\
\text { McGuire; } \\
\text { Walton (Voluntarismo europeu) }\end{array}$ & $\begin{array}{l}\text { Poder social - responsabilidade social } \\
\text { RS deve ir além da expectativa econômica e legal } \\
\text { Contribuir com a RS individualmente, de forma voluntária ou coercitiva } \\
\text { Integração das preocupações ambientais sociais nas operações de negócio e } \\
\text { voluntarismo a partir da interação com os stakeholders. }\end{array}$ \\
\hline $\begin{array}{l}\text { Década de 1970: } \\
\text { Johnson; } \\
\text { Steiner; }\end{array}$ & $\begin{array}{l}\text { Empresa socialmente responsável leva em consideração: funcionários, } \\
\text { fornecedores, distribuidores, comunidades locais e nação. } \\
\text { A RSC deve ajudar a sociedade a alcançar seus objetivos básicos. }\end{array}$ \\
\hline Década de 1980 & Ênfase da ética na tomada de decisão. \\
\hline
\end{tabular}

Fonte: Elaborado com base em Isa (2012).

\subsection{Barreiras de implementação}

Quanto à barreira, esta pode ser definida como um “[...] obstáculo que bloqueia e impede a satisfação de uma necessidade ou a locomoção para um determinado vetor [...]" (CHIAVENATO, 2004, p. 118). Esta definição está dentro da Teoria das Relações Humanas e, portanto, reflete o bloqueio da maneira como a organização trata e gerencia as pessoas, gerando assim sucesso e competitividade. O mesmo conceito pode ser atribuído às implementações de práticas organizacionais que resultem ou possam resultar no seu sucesso, crescimento e desenvolvimento, tornando a organização mais competitiva no mercado.

Adams e Ghaly (2007) dizem, quanto à sustentabilidade, que existe uma necessidade implícita de compreender as principais barreiras que impedem a integração das estratégias de sustentabilidade, pois avaliações genéricas de porque as políticas ambientais acabam falhando não são suficientes e nem são declarações pertinentes. Embora os autores falem genericamente sobre sustentabilidade, aí se insere também o aspecto social (HART; MILSTEIN, 2004). Portanto é indispensável determinar as barreiras que bloqueiam a implementação da norma ISO 26000, impedindo a locomoção para um determinado vetor, no caso, uma empresa com mais responsabilidade social.

Em relação às barreiras de implementação de outras normas, em um estudo com a ISO 9000, que é aceita por muitas organizações, Zeng, Tian e Tam (2007) destacam as seguintes barreiras de implementação: 
- Objetivos de visão curta;

- Expectativa em excesso sobre a norma;

- Requisitos obrigatórios sem comprometimento;

- Seguir a tendência de certificação.

Abdullah (2013) destaca cinco categorias gerais de barreiras de implementação para a ISO 9000 numa empresa governamental na Malásia, que são: as organizacionais, de recursos, as culturais e ambientais e as técnicas.

Já para pequenas e médias empresas, a principal barreira para adoção do sistema de gestão ambiental, assim como para a ISO 14000, é o aspecto econômico, ou seja, o custo de implementação, além da gestão do conhecimento e falta de recursos humanos especializados (BIONDI; FREY; IRALDO, 2000).

Determinar barreiras de implementação, independente das práticas, seja de qualidade com a ISO 9000, ambiental com a ISO 14000 ou social com a ISO 26000, também se torna uma ferramenta para a estratégia empresarial. Pois a função da estratégia é entender o contexto para enfrentar a concorrência, alinhando-se às quatro forças competitivas: clientes, fornecedores, potenciais concorrentes e produtos substitutos (PORTER, 2008). Vale ressaltar que os clientes e fornecedores são stakeholders fundamentais para organizações, e muitos destes stakeholders genericamente influenciaram e contribuíram no desenvolvimento da norma ISO 26000 (BALZAROVA; CASTKA, 2012), mostrando sua importância para as atuais organizações com fins econômicos ou não. Doh e Guay (2006) verificaram que stakeholders, como o governo, ONGs e a comunidade política, são fatores importantes por implementações de RSC nas estruturas organizacionais atuais.

\section{Metodologia}

A metodologia de pesquisa utilizada neste artigo foi a revisão bibliográfica sistemática que, de acordo com Biolchini et al. (2005), é uma metodologia desenvolvida com o objetivo de reunir e avaliar as evidências disponíveis referentes a um tema específico, seguindo uma sequência de fases metodológicas que são rigorosas e muito bem definidas. A revisão sistemática foi construída em torno de uma questão central, que representa o núcleo da investigação, e que se expressa por meio de conceitos e termos específicos, que devem ser abordadas para obtenção de informações relacionadas à questão central.

A questão central deste artigo é: "Quais são as barreiras e motivadores da adoção da ISO 26000 para as organizações?". A partir dessa questão, foram realizadas pesquisas nas bases de dados Web of Science e Scopus para obter artigos com conteúdos capazes de respondê-la. Foram usadas as seguintes palavraschave, de forma genérica, para realizar a pesquisa nas bases de dados: "ISO 26000", "Organizations”,
"Motivators", “Drivers" e “Barriers". O idioma utilizado em todas as buscas foi o inglês.

Para selecionar os estudos identificados nas bases de dados, foram determinados os seguintes critérios de inclusão (CI):

- CI-1: Apresentar conceitos e termos específicos capazes de permitir uma definição ampla da ISO 26000 dentro do contexto da questão central da pesquisa;

- CI-2: Apresentar as implicações que envolvem a adoção da ISO 26000 pelas organizações, sendo suficientes para a determinação e distinção das barreiras e motivadores dessa adoção, permitindo também a criação de uma agenda para estudos futuros.

Depois da realização da busca nas bases de dados, os estudos foram submetidos a dois filtros de pesquisa (FP): o primeiro filtro (FP1) consistiu na leitura do título, resumo e palavras-chave; o segundo filtro (FP2) compreendeu a leitura completa do artigo. Os estudos que foram selecionados nos FP1 e FP2 atenderam a pelo menos um dos critérios de inclusão (CI) estabelecidos anteriormente. Os selecionados tiveram seus dados extraídos e sumarizados para utilização na pesquisa.

Todo o encadeamento do desenvolvimento da revisão bibliográfica sistemática citada acima foi realizado em junho de 2013 e pode ser visualizado na Figura 2.

\section{Resultados}

Como resultado da pesquisa inicial nas bases de dados Web of Science e Scopus, aplicando as palavras-chave determinadas na metodologia, foram obtidos 54 artigos. Esses artigos foram filtrados pelo filtro de pesquisa 1 (FP1), restando apenas 26 artigos de acordo com os critérios de inclusão. No entanto, 4 desses 26 artigos não estavam disponíveis em texto completo nas bases de dados e foram descartados antes de passarem pelo filtro de pesquisa 2 (FP2), mas nenhum dos 22 artigos restantes foi excluído ao passar pelo FP2.

Desse modo, 22 artigos passaram pelos filtros de pesquisa e tiveram seus dados extraídos e sumarizados no Quadro 3 de acordo com os critérios de inclusão.

\section{Discussão}

\subsection{O consenso dos autores sobre a ISO 26000}

Todos os 22 artigos que passaram pelo filtro metodológico forneceram uma conceituação da ISO 26000, portanto, a seguir, está disponível uma 


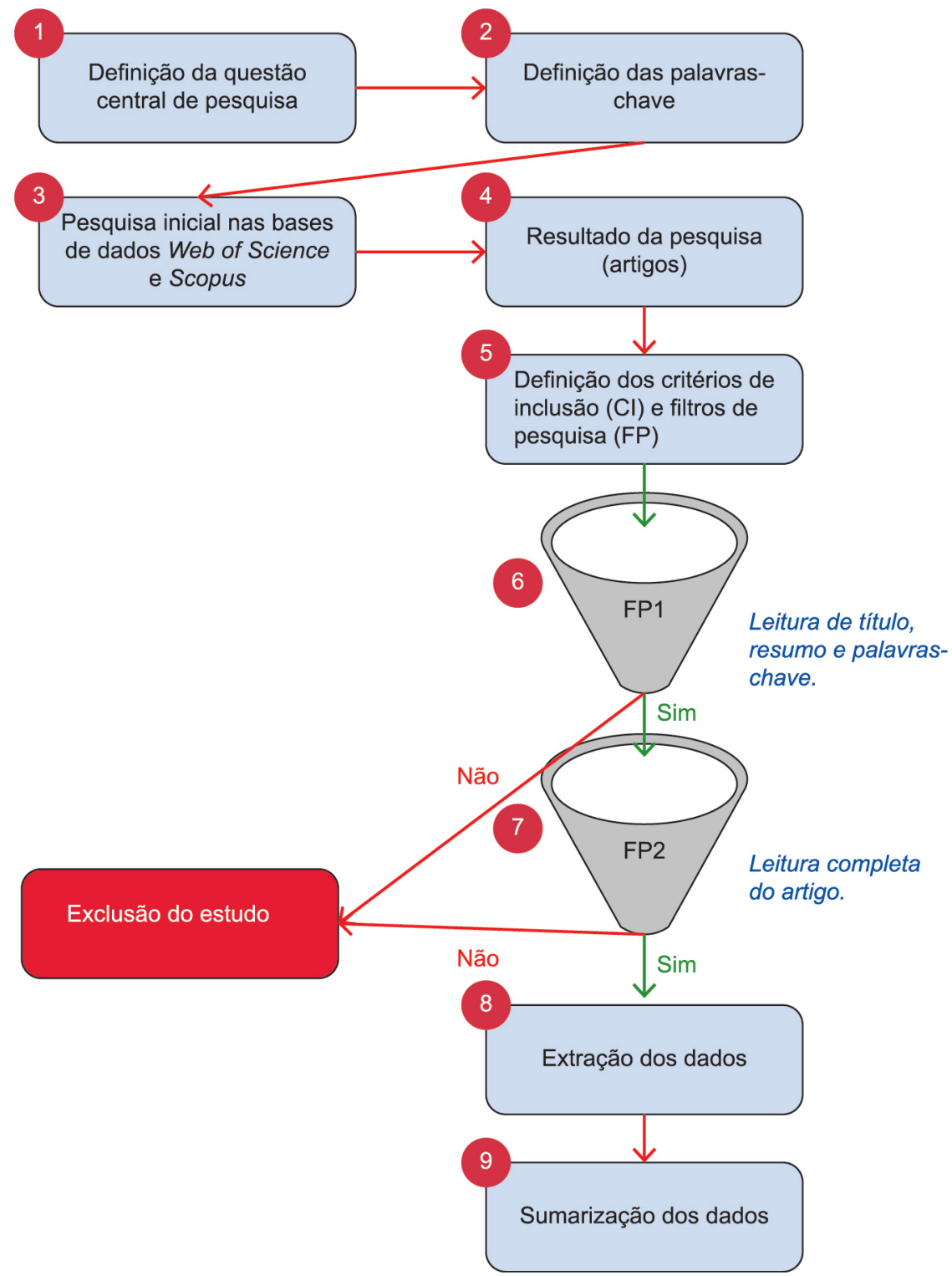

Figura 2. Encadeamento do desenvolvimento da revisão bibliográfica sistêmica. Fonte: Elaborado com base nas etapas da revisão sistemática realizada.

breve discussão sobre as preocupações atuais da aplicabilidade da ISO 26000.

Boström e Hallström (2013), Brodhag (2010), Brodhag e Talière (2006), Henriques (2010), Ortova e Stankova (2011) e Pojasek (2011) ressaltam que a ISO 26000 aplica-se a todos os tipos de organização.

A norma visa auxiliar as organizações a contribuírem com o desenvolvimento sustentável (ASSOCIAÇÃO..., 2010). A justificativa para que uma organização contribua com o desenvolvimento sustentável encontra-se na definição proposta por Hall (2004, p. 30), na qual:

Uma organização é uma coletividade com uma fronteira relativamente identificável, uma ordem normativa (regras), níveis de autoridade (hierarquia), sistemas de comunicação e sistemas de coordenação dos membros (procedimentos); essa coletividade existe em uma base relativamente contínua, está inserida em um ambiente e toma parte de atividades que normalmente se encontram relacionadas a um conjunto de metas; as atividades acarretam consequências para os membros da organização, para a própria organização e para a sociedade.

Fica claro que as organizações geram impactos socioambientais, entretanto, por meio da Responsabilidade Social, os impactos negativos 
Quadro 3. Resultado: relação entre os autores e os critérios de inclusão.

\begin{tabular}{|c|c|c|c|c|}
\hline \multirow{3}{*}{ Artigos } & \multicolumn{4}{|c|}{ Conceitos de Organizações } \\
\hline & \multirow{2}{*}{$\begin{array}{c}\text { Conceito ISO } \\
26000\end{array}$} & \multicolumn{2}{|c|}{ ISO 26000 e Organizações } & \multirow{2}{*}{$\begin{array}{l}\text { Proposta para } \\
\text { Estudos Futuros }\end{array}$} \\
\hline & & Barreiras & Motivadores & \\
\hline Balzarova e Castka (2012) & $\mathrm{X}$ & & & \\
\hline Boström e Hallström (2013) & $X$ & & & \\
\hline Brodhag (2010) & $\mathrm{X}$ & & & \\
\hline Brodhag e Talière (2006) & $\mathrm{X}$ & & & \\
\hline Castka e Balzarova (2008a) & $\mathrm{X}$ & & & \\
\hline Castka e Balzarova (2008b) & $\mathrm{X}$ & & $\mathrm{X}$ & $\mathrm{X}$ \\
\hline Castka e Balzarova (2008c) & $\mathrm{X}$ & & & \\
\hline Hahn (2012a) & $\mathrm{X}$ & $\mathrm{X}$ & $\mathrm{X}$ & \\
\hline Hahn (2012b) & $\mathrm{X}$ & & & \\
\hline Henriques (2010) & $\mathrm{X}$ & $\mathrm{X}$ & & \\
\hline Høivik (2011) & $\mathrm{X}$ & $\mathrm{X}$ & $\mathrm{X}$ & $\mathrm{X}$ \\
\hline Høivik e Shankar (2011) & $X$ & $X$ & $X$ & $\mathrm{X}$ \\
\hline Hřebíček et al. (2012) & $\mathrm{X}$ & & & \\
\hline Merlin, Pereira e Pacheco (2012) & $\mathrm{X}$ & & $\mathrm{X}$ & \\
\hline Mueckenberger e Jastram (2010) & $\mathrm{X}$ & & & $\mathrm{X}$ \\
\hline Ortova e Stankova (2011) & $\mathrm{X}$ & & $\mathrm{X}$ & \\
\hline Pojasek (2011) & $\mathrm{X}$ & & $\mathrm{X}$ & $\mathrm{X}$ \\
\hline Sarotar-Zizek et al. (2012) & $\mathrm{X}$ & & $\mathrm{X}$ & \\
\hline Schwartz e Tilling (2009) & $\mathrm{X}$ & & & $\mathrm{X}$ \\
\hline Siegele e Ward (2007) & $X$ & & & \\
\hline Valmohammadi (2011) & $\mathrm{X}$ & $\mathrm{X}$ & $\mathrm{X}$ & $\mathrm{X}$ \\
\hline Ward (2011) & $X$ & $X$ & & $X$ \\
\hline
\end{tabular}

Fonte: Elaborado pelos autores com base na revisão sistemática.

podem ser minimizados e os impactos positivos maximizados.

A mudança da terminologia Responsabilidade Social Corporativa para Responsabilidade Social a torna comum a todas as organizações (ORTOVA; STANKOVA, 2011), ao mesmo tempo, traz a possibilidade de que cada área, segmento ou organização crie sua própria definição de Responsabilidade Social.

Valcárcel e Lucena (2013), por exemplo, definem a Responsabilidade Social no escopo da Química Analítica, como a consciência do impacto na sociedade, saúde, meio ambiente e agricultura, produzido pela análise de objetos naturais e artificiais, implicando por um lado, a produção sustentável de qualidade, informação química e, por outro, na garantia do que é coerente com a realidade, não dando expectativas falsas e avisos não justificados aos stakeholders.

Hahn (2012b) salienta que a ISO 26000 não fornece quaisquer processos para que a organização construa um sistema de gestão para a responsabilidade social. Brodhag e Taliére (2006) já previam que a principal questão a ser negociada seria a relação entre as iniciativas voluntárias e obrigações vinculativas. A norma prevê que a organização tem que cumprir com a legislação local e com as normas internacionais. O esperado é que as organizações caminhem para além dos limites previstos na lei para contribuir com o desenvolvimento sustentável.

A ISO 26000 não é certificável (CASTKA; BALZAROVA, 2008c; HAHN, 2012b; HENRIQUES, 2010; MUECKENBERGER; JASTRAM, 2010; POJASEK, 2011; SIEGELE; WARD, 2007), ou seja, ela não é avaliada por uma certificadora. Entretanto, espera-se que os stakeholders avaliem a responsabilidade social das organizações (HØIVIK; SHANKAR, 2011; HŘEBÍČEK et al., 2012; VALMOHAMMADI, 2011).

Uma vez que a própria ISO 26000 foi desenvolvida pelo ponto de vista de um grupo de trabalho composto por stakeholders (BALZAROVA; CATSKA, 2012; MUECKENBERGER; JASTRAM, 2010), essa norma foca os stakeholders (CASTKA; BALZAROVA, 2008a), e cabe à organização identificar e engajar-se com seus stakeholders (CASTKA; BALZAROVA, 2008b; MERLIN; PEREIRA; PACHECO, 2012; SIEGELE; WARD, 2007).

Como já questionado por Banerjee (2012, p. 74) na introdução desta pesquisa, as funções econômicas são as necessidades básicas das empresas, então 
[...] o que aconteceria com a comunidade local que é completamente dependente do bem-estar econômico, social e ambiental de uma empresa multinacional?

Essa questão vem de encontro ao exposto por Schwartz e Tiling (2009) que questionam se a ISO 26000 trará qualquer mudança para as pessoas que trabalham em condições precárias nos países de baixa renda. Essa questão é digna de ser investigada e pode ser observada sobre a perspectiva dos stakeholders, pois qual será a capacidade dos stakeholders dos países pobres de avaliar e pressionar o governo e as outras organizações a contribuírem para o desenvolvimento socioambiental?

Mueckenberger e Jastram (2010) reforçam que a norma não é legalmente, mas moralmente, obrigatória. Seu cumprimento baseia-se no anúncio público do autocompromisso, com potencial risco de perda de reputação (sanções públicas) que ocorreria no caso de não cumprimento da norma. Høivik e Shankar (2011) discutem que o comportamento ético e transparente contribui para o desenvolvimento sustentável. Já Valmohammadi (2011) argumenta que a falta de atenção adequada para as questões como auditorias sociais e éticas, falta de transparência nas operações, entre outros, dificultam a adoção de um comportamento socialmente responsável.

O esperado é que as organizações trabalhem, lapidem e transformem a governança organizacional para desenvolver uma cultura organizacional pautada nos sete princípios da responsabilidade social. Dessa forma, as organizações poderão praticar a responsabilidade social norteada pelos temas centrais citados por Hřebíček et al. (2012), Merlin, Pereira e Pacheco (2012), Sarotar-Zizek et al. (2012), Valmohammadi (2011), melhorando o desempenho social (HŘEBÍČEK et al., 2012) e gerando vantagens competitivas.

\subsection{Motivadores e benefícios}

O resultado da revisão bibliográfica sistemática apresentou que nove (9) dos vinte e dois (22) artigos escolhidos apresentavam alguma indicação, alusão ou citação dos motivadores na adoção da ISO 26000 e, consequentemente, a adoção de uma postura responsável socialmente.

Dessa forma, para facilitar a discussão, todos os motivadores citados pelos autores foram dispostos em oito grupos:

- Globalização - competição em mercados internacionais;

- Congruência com sistemas de gestão;

- Reputação (imagem) da empresa;

- Relação com os funcionários e melhora do ambiente organizacional;

- Melhora na relação com stakeholders externos;

- Vantagem competitiva/estratégias;

- Diminuição dos riscos do negócio; e

- Guia para a RSC.

A seguir, serão apresentados alguns exemplos dentro de cada grupo de motivadores, que também são apresentados no Quadro 4, no qual os autores são relacionados aos grupos.

Globalização - competição em mercados internacionais: Castka e Balzarova (2008b) citam que empresas multinacionais adotam a ISO 26000 na busca por legitimidade de suas políticas internas de responsabilidade social, pois isso facilita o acesso a diferentes mercados internacionais. Algo que é compartilhado por Høivik e Shankar (2011). Valmohammadi (2011) também cita as oportunidades

Quadro 4. Relação entre os grupos de motivadores e autores.

\begin{tabular}{|c|c|c|c|c|c|c|c|c|c|}
\hline Grupos/ Autores & 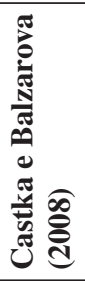 & 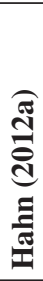 & 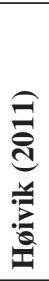 & 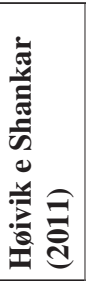 & 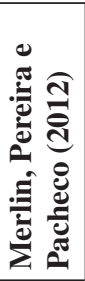 & 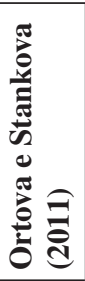 & 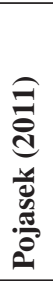 & 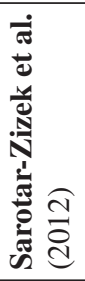 & 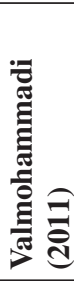 \\
\hline $\begin{array}{l}\text { Globalização: competição em mercados } \\
\text { internacionais }\end{array}$ & $\mathbf{X}$ & & & $\mathbf{X}$ & & & & & $\mathbf{X}$ \\
\hline Congruência com sistemas de gestão & $\mathbf{X}$ & & $\mathbf{X}$ & & $\mathbf{X}$ & & & & \\
\hline Reputação (imagem) da empresa & & & & $\mathbf{X}$ & & & $\mathbf{X}$ & & $\mathbf{X}$ \\
\hline $\begin{array}{l}\text { Relação com os funcionários e melhora do } \\
\text { ambiente organizacional }\end{array}$ & & & & $\mathbf{X}$ & & $\mathbf{X}$ & & $\mathbf{X}$ & $\mathbf{X}$ \\
\hline Melhora na relação com stakeholders externos & $\mathbf{X}$ & & $\mathbf{X}$ & $\mathbf{X}$ & $\mathbf{X}$ & & $\mathbf{X}$ & & $\mathbf{X}$ \\
\hline Vantagem competitiva/estratégias & $\mathbf{X}$ & $\mathbf{X}$ & $\mathbf{X}$ & $\mathbf{X}$ & $\mathbf{X}$ & $\mathbf{X}$ & & & $\mathbf{X}$ \\
\hline Guia para a RSC & & $\mathbf{X}$ & & & & & $\mathbf{X}$ & & \\
\hline Diminuição dos riscos do negócio & & & & $\mathbf{X}$ & & & & & $\mathbf{X}$ \\
\hline
\end{tabular}


de participação em joint-ventures internacionais como um motivador.

Congruência com sistemas de gestão: segundo Castka e Balzarova (2008b), empresas que já adotaram normas internacionais de sistemas de gestão no passado podem ser mais propensas a adotar a ISO 26000. O que tem o consenso de Høivik (2011), que considera a ISO 26000 como um elo valioso para a ISO 14001, por exemplo.

Reputação (imagem) da empresa: a imagem de uma empresa pode ser um motivador importante na adoção da ISO 26000, pois o público reconhece iniciativas voluntárias de responsabilidade social, segundo Pojasek (2011), algo que também pode melhorar a relação com compradores (HØIVIK; SHANKAR, 2011) e, assim, aumentar a reputação corporativa (VALMOHAMMADI, 2011).

Relação com os funcionários e com o ambiente de trabalho: esse é um motivador importante, pois proporciona um ambiente mais saudável e sustentável na organização (ORTOVA; STANKOVA, 2011), melhora a relação da empresa com os funcionários e entre os funcionários, e aumenta o acesso a profissionais talentosos e desejados (HØIVIK; SHANKAR, 2011; SAROTAR-ZIZEK et al., 2012; VALMOHAMMADI, 2011).

Melhora na relação com stakeholders externos: da mesma forma que a adoção da ISO 26000 melhora a relação com os funcionários, ela também traz benefícios para a relação com os stakeholders externos. Pois, muitas vezes, essa necessidade de adoção também é percebida pelos stakeholders, como apresentam Castka e Balzarova (2008b). Além disso, a norma apresenta soluções de conflitos entre stakeholders e organizações e oportunidades de reforço da relação desses dois agentes (HØIVIK, 2011; HØIVIK; SHANKAR, 2011). Com ela, as organizações também podem aumentar sua capacidade de manter clientes e induzir um comportamento responsável sobre eles (MERLIN; PEREIRA; PACHECO, 2012; VALMOHAMMADI, 2011).

Vantagem competitiva/estratégias: motivador importantíssimo, se não o mais importante para as organizações que a adoção da norma pode trazer. Algumas dessas vantagens competitivas são: consolidação frente aos concorrentes, compensação dos custos de implantação pelos benefícios percebidos, aumento da inovação (desenvolvimento de novos negócios), aproveitamento de oportunidades e aumento na capacidade de alcançar resultados (metas) financeiros desejados (CASTKA; BALZAROVA, 2008b; HAHN, 2012a; HØIVIK, 2011; HØIVIK; SHANKAR, 2011; MERLIN; PEREIRA; PACHECO, 2012; ORTOVA; STANKOVA, 2011; VALMOHAMMADI, 2011).

Diminuição dos riscos do negócio: atrelado às vantagens competitivas da adoção da ISO 26000 e, consequentemente, de um comportamento mais responsável socialmente. Høivik e Shankar (2011) dizem que a adoção da RSC é um meio de gerenciar riscos e também de minimizá-los quando se materializam. O mesmo que apresenta Valmohammadi (2011), ao dizer que essa adoção proporciona maior capacidade das organizações de mitigarem os riscos.

Guia para a RSC: por fim, acima de todos esses motivadores e vantagens, a ISO 26000 é primeiramente um importante guia para a RSC. Segundo Pojasek (2011), ela oferece um guia para a organização melhorar a sua credibilidade em relação à RSC. Hahn (2012a) ressalta que para médias e pequenas empresas, que normalmente possuem menos participação em RSC, a norma permite a identificação de definições consensuais de temas centrais, questões de responsabilidade social e sustentabilidade corporativa, que são aspectos interessantes e importantes para essas organizações.

\subsection{Barreiras para implementação}

Como a ISO 26000 é um assunto recente na literatura, é importante que as organizações identifiquem as barreiras da implementação da RSC baseadas na norma, pois é um assunto essencial e considerável para o sucesso da organização que almeja transcender esses limites. Vale ressaltar que, dentre os artigos encontrados, disponíveis no Quadro 3, os que mencionam barreiras de implementação direta ou indiretamente foram apenas 6 .

Valmohammadi (2011, p. 260) classifica de forma clara as barreiras em uma pesquisa com 130 organizações manufatureiras no Irã. A questão relativa às barreiras de implementação no questionário de sua pesquisa foi: "[...] quais são os principais motivadores e barreiras para aplicar as práticas e iniciativas de RSC?". O propulsionador para a definição desta questão foi a constatação do autor de que $85 \%$ dessas organizações esperam ter uma posição de mais sucesso no mercado ao melhorar a identidade corporativa, resultante da implementação de atividades e programas de RSC. Ao analisar a classificação das barreiras dadas pelas organizações, de uma listagem de 7 , o resultado encontrado foi o seguinte (Quadro 5):

Como pode ser observado acima, a principal barreira, e a mais importante para implementar um programa de RSC nas organizações pesquisadas, é a falta de conhecimento e consciência. Tal barreira pode ser ultrapassada, por exemplo, com políticas públicas envolvendo o governo e as universidades para levar o conhecimento às organizações e conscientizá-las da importância da Responsabilidade Social Corporativa em seus processos internos, mostrando seus benefícios sociais e econômicos e enfatizando seu papel na sociedade. Pois grande parte das sete principais 
Quadro 5. Classificação de 7 barreiras para a implementação da ISO 26000 em organizações iranianas.

\begin{tabular}{|c|l|}
\hline Classificação & \multicolumn{1}{c|}{ Barreiras } \\
\hline $1^{\circ}$ & Falta de conhecimento ou consciência de RSC \\
\hline $2^{\circ}$ & $\begin{array}{l}\text { Foco na remoção de obstáculos e atingir metas de curto prazo, ao invés de no desenvolvimento de } \\
\text { estratégias de longo prazo }\end{array}$ \\
\hline $3^{\circ}$ & Falta de conhecimento sobre como implementar a RSC na estratégia da organização \\
\hline $4^{\circ}$ & Falta de comunicação eficaz e a promoção dos stakeholders \\
\hline $5^{\circ}$ & $\begin{array}{l}\text { As empresas privadas acreditam que o governo deve ser responsável pelo desenvolvimento } \\
\text { sustentável e liderança nesse campo }\end{array}$ \\
\hline $6^{\circ}$ & Atos de caridade são sempre entendidos a permanecer em particular \\
\hline $7^{\circ}$ & Mentalidade xenofóbica e em forma de conspiração. \\
\hline
\end{tabular}

áreas da ISO 26000 trata de aspectos essenciais para as organizações, são elas: (1) ambiente; (2) direitos humanos; (3) práticas trabalhistas; (4) governança organizacional; (5) práticas operacionais justas; (6) problemas do consumidor; e (7) contribuição à comunidade e sociedade (PARK; KIM, 2011). Valmohammadi (2011) confirma em seu estudo que a utilização do núcleo principal da ISO 26000 é significativamente relacionada ao maior sucesso da empresa no contexto iraniano, sendo esse sucesso tangível à redução de custos e crescimento das receitas.

Num estudo de implementação da Responsabilidade Social Corporativa em pequenas e médias empresas na Noruega, Høivik e Shankar (2011) identificaram 6 barreiras de implementação, que são: 1. Recursos (humanos e financeiros) das pequenas e médias empresas; 2. Sensibilização para as questões de responsabilidade social e de prestação de contas; 3 . Falta de compreensão de situações locais no exterior; 4. Limitação financeira, relacionada à confiança dos investidores; 5 . Poder de barganha no estabelecimento de padrões, especialmente em áreas internacionais; 6. Ferramentas para implementação, pois a maioria é projetada para corporações multinacionais. Estes resultados diferem da classificação das empresas iranianas por Valmohammadi (2011), provavelmente por causa do contexto e nicho de mercado, além das diferenças culturais dos países que podem influenciar o desempenho da responsabilidade social (MIRAS-RODRÍGUEZ; CARRASCO-GALLEGO; ESCOBAR-PÉREZ, 2013).

Segundo Henriques (2010), uma possível barreira é o impacto da ISO 26000 sobre o comércio e sua relação à Organização Mundial do Comércio, pois se esta norma tiver a mesma função que as outras normas ISO, como a ISO 14000 e a ISO 9000, formar-se-ão barreiras técnicas comerciais. Portanto, uma barreira comercial com base na ISO 26000 teria um grande impacto sobre a China e a Índia, por exemplo, pelo fato desses países não cumprirem alguns aspectos relacionados aos direitos humanos.

Uma norma de responsabilidade social ISO é um potencial para a adoção da responsabilidade social, desde que a organização não a considere irrelevante, inaplicável ou incompreendida. Além disso, há temores de que ela poderia, inadvertidamente, causar mais pressão global sobre os pequenos produtores se estes não satisfizerem as orientações da norma, limitando o acesso aos mercados para os produtos dos países em desenvolvimento (WARD, 2011). Hahn (2012a) chega a uma conclusão similar, levantando mais uma barreira: que a ISO 26000 deveria ser mais útil na incorporação de questões sobre responsabilidade social em empresas que estão iniciando suas atividades, pois normalmente essas empresas são de países em desenvolvimento.

Høivik (2011) ressalta dois obstáculos de implementação: 1. A norma ISO 26000 como um padrão do processo é muito bem adequada para as características da empresa e, portanto, torna a companhia muito específica, assim o conhecimento fica profundamente enraizado na empresa, não permitindo a replicação, então acaba se tornando mais-valia, como uma "patente", e fica exclusivo ao know-how; 2. Obstáculo relacionado com a maneira que este conhecimento pode ser compartilhado.

Conhecer as barreiras para superá-las é fundamental, pois os executivos reconhecem que a Responsabilidade Social Corporativa é importante para o sucesso da empresa, entretanto admitem a luta com a incerteza das necessidades sociais não satisfeitas ou como as questões sociais afetarão suas empresas. Do ponto de vista acadêmico, há muita pesquisa ligando RSC ao sucesso competitivo, no entanto, os esforços estão em entender aos avanços conceituais e teóricos e testes empíricos entre RSC e o desempenho da empresa (GALBREATH, 2009). Aqui é possível identificar mais uma barreira: a falta de ligação e o alinhamento da RSC com a estratégia organizacional, a qual não foi citada pelos autores encontrados nesta pesquisa, mas que é importante, pois a estratégia melhora a competição da empresa (PORTER, 2008).

Para comparar os artigos em relação às barreiras de implementação da ISO 26000 na organização corporativa, os dados foram sintetizados em 10 barreiras principais, 9 encontradas nos artigos resultantes da pesquisa, como consta na metodologia, e 1 indiretamente, de acordo com a fundamentação 
teórica e discussão. O Quadro 6 mostra a síntese das barreiras e quais autores as citam.

De acordo com a análise comparativa, as barreiras mais citadas são:

Comercial (nacional e internacional): pois pode limitar o acesso das empresas ao mercado, principalmente aquelas que não valorizam os direitos humanos, então há esta guerra para que a norma não seja um fator de comércio e, consequentemente, pressão para que não seja disseminada. Para a ISO 9000, as empresas não encontram tal barreira, pois se motivam para a melhora da participação de mercado que esta norma pode trazer (ZENG; TIAN; TAM, 2007).

Falta de compreensão da ISO 26000: as organizações podem não compreendê-la como um todo, pensando que ela é irrelevante e inaplicável. O contrário é constatado quanto à barreira de implementação da ISO 9000, pois as empresas têm expectativa em excesso sobre a norma, então se entusiasmam com os benefícios que ela pode trazer, como produtividade, eficiência e participação de mercado, esquecendo-se, no entanto, dos problemas que podem ser gerados (ZENG; TIAN; TAM, 2007). Entretanto, na pesquisa de Abdullah (2013), a falta de entendimento, no caso da ISO 9000, constitui a principal barreira na categoria de barreiras técnicas.

Falta de ferramentas: a maioria das ferramentas de implementação da responsabilidade social são projetadas para multinacionais e não para pequenas e médias empresas, ou empresas que estão iniciando a implementação. A mesma barreira é constatada por Zeng, Tian e Tam (2007) para a ISO 9000, em que $8 \%$ das empresas entrevistadas a classificaram como a principal barreira de implementação desta norma (ZENG; TIAN; TAM, 2007). Pode-se dizer o mesmo do sistema de gestão ambiental, pois as pequenas e médias empresas carecem de ferramentas humanas especializadas, as quais são essenciais para o desempenho da gestão (BIONDI; FREY; IRALDO, 2000).

Falta de sensibilidade ao tema: as corporações podem não ser sensíveis ao tema de responsabilidade social, provavelmente e consequentemente pela falta de compreensão do tema, portanto da própria ISO 26000.

A 'falta de comunicação', 'foco no curto prazo', 'gestão do conhecimento', 'receio em não cumprir a norma' e 'recursos financeiros' foram citados por apenas um artigo, entretanto não significa que são menos importantes, mas que são barreiras ou obstáculos, que necessitam de mais estudos práticos.

Para confirmar a importância destas barreiras menos citadas, é possível encontrá-las em outras normas: o 'foco no curto prazo' é similar à barreira 'objetivos de visão curta', destacada por Zeng, Tian e Tam (2007), em que $42 \%$ dos respondentes da pesquisa classificaram-na como a principal barreira de implementação da ISO 9000, pois as empresas focam apenas os benefícios diretos da norma. Quanto ao tópico 'recursos financeiros', embora citado apenas por Høivik e Shankar (2011), pode ser considerado a principal barreira para o sistema de gestão ambiental em pequenas e médias empresas (BIONDI; FREY; IRALDO, 2000).

Já a 'falta de comunicação', na pesquisa de Abdullah (2013), foi a barreira menos importante na categoria ‘barreiras organizacionais' para a adoção

Quadro 6. Relação entre os grupos de barreiras e autores.

\begin{tabular}{|l|c|c|c|c|c|}
\hline \multicolumn{1}{|c|}{ Grupos/ Autores } & & & & & \\
\hline $\begin{array}{l}\text { Falta de alinhamento da RSC com a } \\
\text { estratégia organizacional* }\end{array}$ & & & $\mathbf{X}$ & $\mathbf{X}$ & $\mathbf{X}$ \\
\hline Comercial (Nacional e Internacional) & & & & $\mathbf{X}$ & $\mathbf{X}$ \\
\hline Falta de compreensão da ISO 26000 & & & & $\mathbf{X}$ & $\mathbf{X}$ \\
\hline Falta de comunicação & & & & $\mathbf{X}$ \\
\hline Falta de ferramentas & & & & $\mathbf{X}$ & $\mathbf{X}$ \\
\hline Falta de sensibilidade ao tema & & & & $\mathbf{X}$ & $\mathbf{X}$ \\
\hline Foco no curto prazo & & & & & $\mathbf{X}$ \\
\hline Gestão do conhecimento & & & & \\
\hline Receio em não cumprir a norma & & & & \\
\hline Recursos financeiros & & & & \\
\hline
\end{tabular}

*barreira encontrada na fundamentação teórica, mas importante para o tema. 
da ISO 9000. Vale ressaltar, também, que a 'gestão do conhecimento' é uma ferramenta fundamental, pois, assim como para a gestão ambiental, a responsabilidade social não é uma questão fácil de ser interpretada e aplicada, principalmente nas pequenas e médias empresas (BIONDI; FREY; IRALDO, 2000).

A barreira 'falta de alinhamento da RSC com a estratégia organizacional' não foi mencionada pelos artigos que passaram pelos filtros, mas foi encontrada pelos autores deste artigo no aprofundamento teórico do estudo e na discussão do texto. Ela também é um motivador, pois o alinhamento com a estratégia organizacional traz vantagens competitivas à empresa (CASTKA; BALZAROVA, 2008b; HAHN, 2012a; HØIVIK, 2011; HØIVIK; SHANKAR, 2011; MERLIN; PEREIRA; PACHECO, 2012; ORTOVA; STANKOVA, 2011; VALMOHAMMADI, 2011).

\section{Conclusão e estudos futuros}

O objetivo proposto pelo trabalho foi realizar uma revisão sistemática da literatura para reunir os conceitos da ISO 26000, identificar os motivadores e barreiras para sua adoção, e criar uma agenda para estudos futuros. A Figura 3 apresenta um resumo dos conceitos, barreiras e motivadores relacionados à ISO 26000, identificados na revisão sistemática, e o Quadro 7 apresenta uma agenda proposta para estudos futuros. Portanto, pode-se afirmar que os objetivos propostos foram alcançados.
O trabalho identificou oito grupos de motivadores para implementação da ISO 26000 (Quadro 4 e Figura 3) e dez grupos de barreiras de implementação (Quadro 6 e Figura 3). Dessas dez, nove foram citadas pelos autores dos artigos resultantes do filtro metodológico (Quadro 6). A barreira não citada trata-se da 'falta de alinhamento da RSC com a Estratégia organizacional'.

A partir do levantamento realizado observou-se que existe um vasto campo para estudar a capacidade das organizações de implementarem a ISO 26000. Høivik (2011) expôs que a implementação da ISO 26000 por uma empresa não pode ser copiada por outra, devido às características específicas a cada organização. No entanto, por se tratar da responsabilidade com a sociedade, patentear esse conhecimento, implicaria em falta de responsabilidade social.

Da mesma forma, Heras-Saizarbitoria e Boiral (2013) desenvolveram um trabalho, cuja principal contribuição foi fornecer uma revisão sistemática da literatura, com destaque para ISO 9001 e ISO 14001, para analisar as principais conclusões dos estudos realizados a partir de diferentes perspectivas e propor diferentes possibilidades para pesquisas futuras. Este estudo procurou criar uma agenda para estudos futuros relacionados à ISO 26000, que, de acordo com a metodologia estabelecida e artigos selecionados, resultou no Quadro 7.

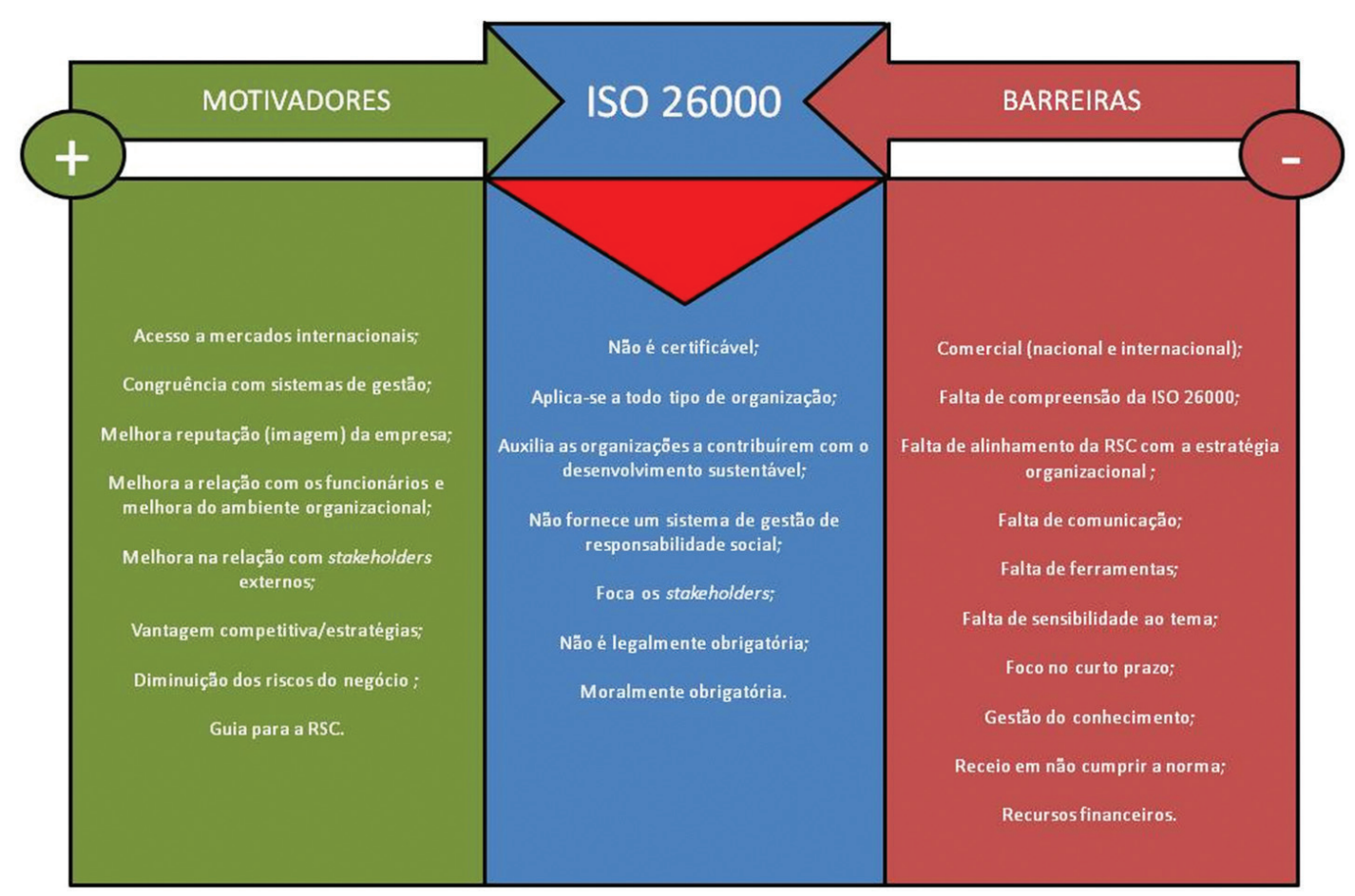

Figura 3. Resumo dos conceitos, barreiras e motivadores relacionados à ISO 26000 identificados no trabalho. Fonte: Elaborado pelos autores com base nos resultados da revisão sistemática. 
Quadro 7. Sugestões para estudos futuros encontradas nesta pesquisa.

\begin{tabular}{|c|c|}
\hline Autores & Sugestões para Estudos Futuros \\
\hline $\begin{array}{c}\text { Castka e Balzarova } \\
(2008 b)\end{array}$ & $\begin{array}{l}\text { - Pesquisas empíricas sobre a difusão da ISO } 26000 . \\
\text { - Observar como países desenvolvidos e em desenvolvimento lidarão com a ISO } 26000 . \\
\text { - Pesquisas focadas em indústrias específicas serão necessárias para apoiar/analisar as práticas } \\
\text { específicas da norma, bem como para analisar sua influência na cadeia de suprimentos. }\end{array}$ \\
\hline Høivik (2011) & $\begin{array}{l}\text { - Mapear o desafio de gerir o conhecimento que a ISO } 26000 \text { traz. } \\
\text { - Gestão do conhecimento versus ISO } 26000 .\end{array}$ \\
\hline $\begin{array}{l}\text { Høivik e Shankar } \\
\qquad(2011)\end{array}$ & $\begin{array}{l}\text { - Relacionar e estudar o efeito da ISO } 26000 \text { em pequenas e médias empresas. } \\
\text { - Como medir o aumento em capital social e confiança devido à adoção de uma norma de } \\
\text { responsabilidade social. }\end{array}$ \\
\hline $\begin{array}{c}\text { Mueckenberger e } \\
\text { Jastram (2010) }\end{array}$ & $\begin{array}{l}\text { - Recomenda-se que outras pesquisas se baseiem em entrevistas pessoais e estudos de caso } \\
\text { sobre o nível organizacional, capturando as impressões pessoais dos stakeholders. }\end{array}$ \\
\hline Pojasek (2011) & - Integrar a ISO 26000 num sistema de gestão sustentável. \\
\hline $\begin{array}{l}\text { Schwartz e Tilling } \\
(2009)\end{array}$ & $\begin{array}{l}\text { - A ISO } 26000 \text { trará mudanças para as pessoas que trabalham em condições precárias nos } \\
\text { países de baixa renda, ou apenas vai garantir às empresas mais lucros? }\end{array}$ \\
\hline $\begin{array}{l}\text { Valmohammadi } \\
\qquad(2011)\end{array}$ & $\begin{array}{l}\text { - Investigar a importância das práticas de RSC e sua iniciativa, os motivadores e barreiras em } \\
\text { outros países. } \\
\text { - Comparação transnacional de práticas e iniciativas de responsabilidade social também } \\
\text { pode fornecer um maior conhecimento sobre a importância das práticas de RSC para a } \\
\text { sustentabilidade de uma organização. } \\
\text { - Pesquisas que incluem as percepções e visões de outros empregados, além de gestores, a fim } \\
\text { de proporcionar uma visão mais holística do estudo. } \\
\text { - Recomendam-se mais pesquisas que incorporem outras variáveis moderadoras como o } \\
\text { ambiente legal e regulamentar dos países. }\end{array}$ \\
\hline Ward (2011) & $\begin{array}{l}\text { - Que tipo de democracia adotaria os padrões da ISO } 26000 \text { já que estão cada vez mais se } \\
\text { aprofundando em áreas de interesse público (estado)? } \\
\text { - O que seria um ajuste perfeito entre a democracia interna ISO e a democracia externa da } \\
\text { esfera política em estados cujas futuras escolhas políticas dos cidadãos podem ser afetadas, ou } \\
\text { suas vidas impactadas, pela ISO 26000? }\end{array}$ \\
\hline
\end{tabular}

Fonte: Elaborado pelos autores com base na revisão sistemática.

Além dos temas para estudos futuros encontrados, outros poderiam investigar como as parcerias entre universidades e indústrias podem contribuir com a promoção da adoção da responsabilidade social pelas organizações. Outra questão que pode ser investigada é o papel dos Estados e da Organização Mundial do Comércio na difusão da ISO 26000. Além destes, criar um modelo de implementação da ISO 26000 para as empresas, ressaltando as pequenas e médias empresas, também é uma lacuna fundamental para novas pesquisas. Portanto esta pesquisa contribui para a área da Responsabilidade Social guiada pela norma ISO 26000 revisando e reunindo seus conceitos, motivadores e barreiras de implementação, elucidando estes aspectos e preenchendo uma importante lacuna de pesquisa.

\section{Referências}

ABDULLAH, S. Implementation barriers of ISO 9000 within the Malaysian local government. International Journal of Quality \& Reliability Management, v. 30, n. 8, p. 853-876, 2013. http://dx.doi.org/10.1108/ IJQRM-Dec-2011-0160
ASSOCIAÇÃO BRASILEIRA DE NORMAS TÉCNICAS - ABNT. NBR ISO 26000: diretrizes sobre responsabilidade social. Rio de Janeiro, 2010. 110 p. Disponível em: <http://www.pessoacomdeficiencia. gov.br/app/sites/default/files/arquivos/[field_generico_ imagens-filefield-description]_65.pdf> Acesso em: 11 jun. 2013.

ADAMS, M. A.; GHALY, A. E. Determining barriers to sustainability within the Costa Rican coffee industry. Sustainable Development, v. 15, n. 4, p. 229-241, 2007. http://dx.doi.org/10.1002/sd.314

ARNOLD, J.; ROBERTSON, I. T.; COOPER, C. L. Work psychology. Pitman: London, 1991.

BALZAROVA, M.; CASTKA, P. Stakeholders' influence and contribution to social standards development: the case of multiple stakeholder approach to ISO 26000 development. Journal of Business Ethics, v. 111, n. 2, p. 265-279, 2012. http://dx.doi.org/10.1007/ s10551-012-1206-9

BANERJEE, S. B. Corporate social responsibility: the good, the bad and the ugly. Critical Sociology, v. 34, n. 1 , p. 51-79, 2012. http://dx.doi. org/10.1177/0896920507084623

BIOLCHINI, J. et al. Systematic review in software engineering. Rio de Janeiro: Systems Engineering and 
Computer Science Departament: COPPE/UFRJ, 2005.

(Technical Report RT - ES 679/05).

BIONDI, V.; FREY, M.; IRALDO, F. Environmental Management Systems and SMEs. Greener Management International, n. 29, p. 55-69, 2000.

BOSTRÖM, M.; HALLSTRÖM, K. T. Global multistakeholder standard setters: how fragile are they? Journal of Global Ethics, v. 9, n. 1, p. 93-110, 2013. http://dx.doi.org/10.1080/17449626.2013.773180

BRODHAG, C. A differentiated approach for sustainable consumption and production policies. Natural Resources Forum, v. 34, n. 1, p. 63-70, 2010. http://dx.doi. org/10.1111/j.1477-8947.2010.01276.x

BRODHAG, C.; TALIÈRE, S. Sustainable development strategies: tools for policy coherence. Natural Resources Forum, v. 30, n. 2, p. 136-145, 2006. http://dx.doi. org/10.1111/j.1477-8947.2006.00166.x

CASTKA, P.; BALZAROVA, M. A. Adoption of social responsibility through the expansion of existing management systems. Industrial Management and Data Systems, v. 108, n. 3, p. 297-309, 2008a. http:// dx.doi.org/10.1108/02635570810858732

CASTKA, P.; BALZAROVA, M. A. ISO 26000 and supply chains-on the diffusion of the social responsibility standard. International Journal of Production Economics, v. 111, n. 2, p. 274-286, 2008b. http:// dx.doi.org/10.1016/j.ijpe.2006.10.017

CASTKA, P.; BALZAROVA, M. A. Social responsibility standardization: guidance or reinforcement through certification? Human Systems Management, v. 27, n. 3, p. 231-242, 2008 c.

CASTKA, P.; BALZAROVA, M. A. The impact of ISO 9000 and ISO 14000 on standardisation of social responsibility-an inside perspective. International Journal of Production Economics, v. 113, n. 1, p. 74-87, 2008d. http://dx.doi.org/10.1016/j.ijpe.2007.02.048

CHIAVENATO, I. Introdução à teoria geral da administração. 3. ed. Rio de Janeiro: Elsevier, 2004. 494 p. (Edição compacta).

DOH, J. P.; GUAY, T. R. Corporate Social Responsibility, public policy, and NGO activism in Europe and the United States: an institutional-stakeholder perspective. Journal of Management Studies, v. 43, n. 1, p. 47-73, 2006. http://dx.doi.org/10.1111/j.1467-6486.2006.00582.x

DRUCKER, P. F. The new society of organizations. Harvard Business Review, v. 70, n. 5, p. 95, 1992. PMid:10121319.

ELKINGTON, J. Towards the suitable corporation: win-win-win business strategies for sustainable development. California Management Review, v. 36, n. 2, p. 90-100, 1994. http://dx.doi.org/10.2307/41165746

GALBREATH, J. Building corporate social responsibility into strategy. European Business Review, v. 21, n. 2, p. 109-127, 2009. http://dx.doi. org/10.1108/09555340910940123

GARCIA, B. G. Responsabilidade social das empresas: a contribuição das universidades. São Paulo: Peirópolis, 2006.

HAHN, R. ISO 26000 and the standardization of strategic management processes for sustainability and Corporate Social Responsibility. Business Strategy and the
Environment, v. 22, n. 7, p. 442-455, 2012a. http:// dx.doi.org/10.1002/bse. 1751

HAHN, R. Standardizing Social Responsibility? New perspectives on guidance documents and management system standards for sustainable development. IEEE Transactions on Engineering Management, v. 59, n. 4, p. 717-727, 2012b. http://dx.doi.org/10.1109/ TEM.2012.2183639

HALL, R. H. Organizações: estruturas, processos e resultados. São Paulo: Pearson Prentice Hall, 2004.

HART, S. L.; MILSTEIN, M. B. Criando valor sustentável. RAE Executivo, v. 3, n. 2, p. 65-79, 2004.

HENRIQUES, A. ISO 26000: a standard for human rights? Sustainability Accounting, Management and Policy Journal, v. 1, n. 1, p. 103-105, 2010.

HERAS-SAIZARBITORIA, I.; BOIRAL, O. ISO 9001 and ISO 14001: towards a research agenda on management system standards. International Journal of Management Reviews, v. 15, n. 1, p. 47-65, 2013. http://dx.doi.org/10.1111/j.1468-2370.2012.00334.x

HØIVIK, H. W. Embedding CSR as a learning and knowledge creating process: the case for SMEs in Norway. Journal of Management Development, v. 30, n. 10, p. 1067-1084, 2011. http://dx.doi. org/10.1108/02621711111182547

HØIVIK, H. W.; SHANKAR, D. How can SMEs in a cluster respond to global demands for corporate responsibility? Journal of Business Ethics, v. 101, n. 2, p. 175-195, 2011. http://dx.doi.org/10.1007/s10551-010-0708-6

HOLT, K. Management and organization through 100 years. Technovation, v. 19, n. 3, p. 135-140, 1999. http:// dx.doi.org/10.1016/S0166-4972(98)00113-8

HŘEBÍČEK, J. et al. Corporate performance indicators for agriculture and food processing sector. Acta Universitatis Agriculturae et Silviculturae Mendelianae Brunensis, v. 60, n. 4, p. 121-132, 2012. http://dx.doi.org/10.11118/ actaun201260040121

ISA, S. M. Corporate Social Responsibility: what can we learn from the stakeholders? Procedia: Social and Behavioral Sciences, v. 65, p. 327-337, 2012.

KALYAR, M. N.; RA, N.; KALYAR, A. N. Factors affecting corporate social responsibility: an empirical study. Systems Research and Behavioral Science, v. 505, n. 4, p. 495-505, 2013. http://dx.doi.org/10.1002/sres.2134 MASLOW, A. Motivação e personalidade. New York: Harper \& Row, 1954.

MERLIN, F. K.; PEREIRA, V. L. D. V.; PACHECO, W. Sustainable development induction in organizations: a convergence analysis of ISO standards management tools' parameters. Work: A Journal of Prevention, Assessment and Rehabilitation, v. 41, p. 2736-43, 2012. Supplement 1.

MIRAS-RODRÍGUEZ, M. M.; CARRASCO-GALLEGO, A.; ESCOBAR-PÉREZ, B. Are socially responsible behaviors paid off equally? A cross-cultural analysis. Corporate Social Responsibility and Environmental Management, 2013. No prelo.

MUECKENBERGER, U.; JASTRAM, S. Transnational norm-building networks and the legitimacy of Corporate Social Responsibility standards. Journal of Business 
Ethics, v. 97, n. 2, p. 223-239, 2010. http://dx.doi. org/10.1007/s10551-010-0506-1

ORTOVA, M.; STANKOVA, E. The preparedness of certain companies to implement the ISO 26000 standard. In: INTERNATIONAL CONFERENCE LIBEREC ECONOMIC FORUM, 10., 2011, Liberec, Czech Republic. Proceedings... Liberec: Technická Univerzita v Liberci, 2011. p. 372-381.

PARK, J. Y.; KIM, S. W. Global corporate social responsibility standard, ISO 26000 and its effect on the society. Asian Journal on Quality, v. 12, n. 3, p. 315-322, 2011. http:// dx.doi.org/10.1108/15982681111187146

POJASEK, R. B. ISO 26000 guidance on social responsibility. Environmental Quality Management, v. 20, n. 3, p. 85-93, 2011. http://dx.doi.org/10.1002/tqem.20292

PORTER, M. E. The five competitive forces that shape strategy. Harvard Business Review, v. 86, n. 1, p. 78-93, 2008. PMid:18271320.

QI, G. et al. ISO and OHSAS certifications: how stakeholders affect corporate decisions on sustainability. Management Decision, v. 51, n. 10, p. 1983-2005, 2013. http://dx.doi. org/10.1108/MD-11-2011-0431

SCHWARTZ, B.; TILLING, K. "ISO-lating" corporate social responsibility in the organizational context: a dissenting interpretation of ISO 26000. Corporate Social Responsibility and Environmental Management, v. 16, n. 5, p. 289-299, 2009. http://dx.doi.org/10.1002/csr.211

SAROTAR-ZIZEK S. et al. Empirical data about social responsibility in Slovenia. 20th Interdisciplinary Information Management Talks, v. 38, p. 215-229, 2012.

SIEGELE, L.; WARD, H. Corporate social responsibility: a step towards stronger involvement of business in MEA implementation? Review of European Community \& International Environmental Law, v. 16, n. 2, p. 135-144, 2007. http://dx.doi. org/10.1111/j.1467-9388.2007.00552.x

VAALAND, T. I.; HEIDE, M.; GRØNHAUG, K. Corporate social responsibility: investigating theory and research in the marketing context. European Journal of Marketing, v. 42, n. 9-10, p. 927-953, 2008. http:// dx.doi.org/10.1108/03090560810891082

VALMOHAMMADI, C. Investigating corporate social responsibility practices in Iranian organizations: an ISO 26000 perspective. Business Strategy Series, v. 12, n. 5, p. 257-263, 2011. http://dx.doi. org/10.1108/17515631111166898

VALCÁRCEL, M.; LUCENA, R. Synergistic relationships between analytical chemistry and written standards. Analytica Chimica Acta, v. 788, p. 1-7, 2013. PMid:23845474. http://dx.doi.org/10.1016/j. aca.2013.04.008

WARD, H. The ISO 26000 International guidance standard on social responsibility: implications for public policy and transnational democracy. Theoretical Inquiries in Law, v. 12, n. 2, p. 665-718, 2011. http://dx.doi. org/10.2202/1565-3404.1282

WORLD COMMISSION ON ENVIRONMENT AND DEVELOPMENT. Our common future. Oxford: Oxford University Press, 1987.

ZENG, S. X.; TIAN, P.; TAM, C. M. Overcoming barriers to sustainable implementation of the ISO 9001 system. Managerial Auditing Journal, v. 22, n. 3, p. 244-254, 2007. http://dx.doi.org/10.1108/02686900710733125 